\title{
Airway arteriovenous malformation in pregnancy
}

\author{
Jack Diep, MD • Kartik Dandu, MD • Ming Xiong, MD, PhD • \\ Steven M. Shulman, MD, MS • Antonio J. Gonzalez-Fiol, MD
}

Received: 24 May 2017/Revised: 1 June 2017/Accepted: 19 June 2017/Published online: 22 June 2017

(C) Canadian Anesthesiologists' Society 2017

A 24-yr-old woman (body mass index $35.7 \mathrm{~kg} \cdot \mathrm{m}^{-2}$ ) presented for an elective repeat Cesarean delivery. Her past medical history was significant for nasal polyps, chronic sinusitis, and sporadic arteriovenous malformations (AVMs) of her face, tongue, and larynx. Nine years earlier, she had undergone laser ablation of a supraglottic lesion and excision of a nasal polyp that required a year-long tracheostomy. Her obstetrical history included Cesarean delivery for arrest of labour (age $19 \mathrm{yr}$ ) and scheduled Cesarean delivery (age 20 yr). Both procedures were performed under epidural anesthesia with careful dose titration to attain a surgical level. Her orofacial AVMs were not as extensive at the time, and there were no complications.

Oral and maxillofacial AVMs are rare in parturients, but when present they may result in airway compromise. These vascular lesions are usually congenital but may also occur sporadically. ${ }^{1}$ Although the pathogenesis of these lesions is unclear, they tend to grow during pregnancy, ${ }^{2}$ likely attributable to both hemodynamic and hormonal factors. The lesions are likely to bleed, and their accelerated growth during pregnancy may lead to ulceration, rupture, and/or hemorrhage. Impending ulceration and hemorrhage are typically preceded by pain, pruritus, or enlargement. When the AVMs enlarge, an overlying bruit with increasing intensity may be heard.

An otolaryngology and/or vascular surgery consultation is essential early in pregnancy to evaluate the lesions and to determine if devascularization (or removal) of the AVM is necessary. Preoperative imaging and elective tracheostomy may be warranted in patients with unstable AVMs, signs of airway obstruction, or symptoms of a concomitant spinal AVM (precluding neuraxial anesthesia). Preoperative embolization of feeding arteries can reduce the size of oral AVMs. Blood products should be readily available at

J. Diep, MD ( $\varangle) \cdot$ M. Xiong, MD, PhD

S. M. Shulman, MD, MS

Department of Anesthesiology \& Perioperative Medicine, Rutgers New Jersey Medical School, Newark, NJ, USA

e-mail: diepja@njms.rutgers.edu

K. Dandu, MD

Department of Otolaryngology, Rutgers New Jersey Medical

School, Newark, NJ, USA

A. J. Gonzalez-Fiol, MD

Department of Anesthesiology, Yale School of Medicine,

New Haven, CT, USA 

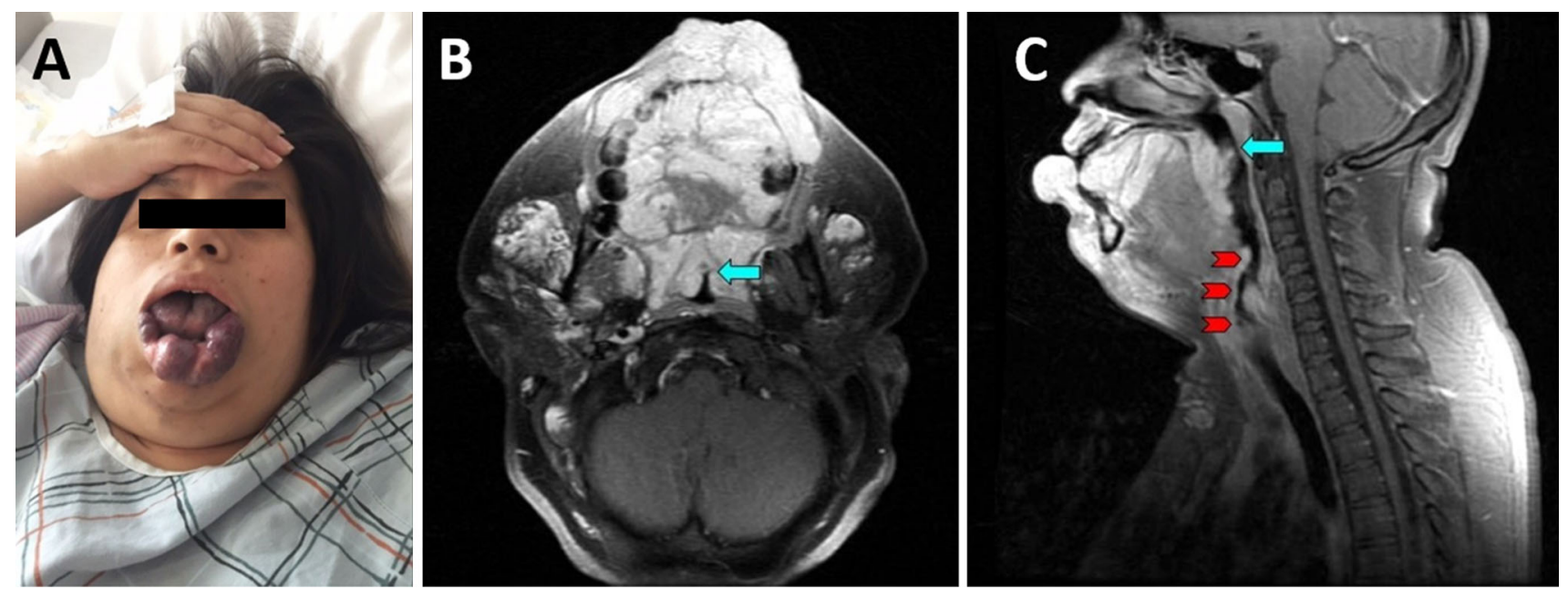

Figure A) Frontal view of patient's face shows significant tongue and multiple lower lip AVMs, as well as bilateral neck enlargement (right greater than left) secondary to extensive AVMs in the soft tissue. B) Axial T1 post contrast MRI head. There is an enhancing extensive, multi-lobulated malformation involving the bilateral softs tissues of the neck and extension into the oronasopharynx and larynx. There is resulting oropharyngeal and laryngeal stenosis with the narrowest point measuring $10 \mathrm{~mm} \times 3 \mathrm{~mm}$ (blue arrow). The right neck malformation extends from the peri-maxillary soft tissues down to the supraclavicular region. The malformation involves the right buccal space, lateral wall of right orbit, right masticator space, right parotid gland, right submandibular space and subcutaneous soft tissue along the sternocleidomastoid muscle. C) Sagittal T1 post contrast

the time of operation. As airway instrumentation should be avoided, neuraxial anesthesia is strongly encouraged.

Conflict of interest None declared.

Editorial responsibility This submission was handled by Dr. Hilary P. Grocott, Editor-in-Chief, Canadian Journal of Anesthesia.

Funding None.
MRI of the head and neck. The malformation involves the lower lip, the tongue muscle, soft palate with narrowing of the oropharynx. The malformation involves bilateral pharyngeal tonsils, bilateral oropharyngeal submucosa, right carotid space, bilateral lingual spaces, right retropharyngeal submucosa. There is stenosis noted at the larynx secondary to asymmetry of malformation, greater on the right. The prevertebral space is involved bilaterally. There is less extensive malformation in the left neck. The malformation involves the left lower lip, left submandibular space around the mandibular angle, left mylohyoid muscle. There are multiple enhancing lesions in the sternal notch. Multifocal stenosis of airway (indicated by three red arrows). Narrowest point of oropharyngeal stenosis measuring $10 \mathrm{~mm}$ $\times 3 \mathrm{~mm}$ (indicated by top blue arrow)

\section{References}

1. Chen W, Wang $J, L i J, X u L$. Comprehensive treatment of arteriovenous malformations in the oral and maxillofacial region. $\mathrm{J}$ Oral Maxillofac Surg 2005; 63: 1484-1488.

2. Kohout MP, Hansen M, Pribaz JJ, Mulliken JB. Arteriovenous malformations of the head and neck: natural history and management. Plast Reconstr Surg 1998; 102: 643-654. 